\title{
(2) \\ () OPEN ACCESS \\ Prognostic predictors relevant to end-of-life palliative care in Parkinson's disease and related disorders: a systematic review
}

\author{
Umer Akbar 이, ${ }^{1}$ Robert Brett McQueen, ${ }^{2}$ Julienne Bemski, ${ }^{2}$ Julie Carter, ${ }^{2}$ \\ Elizabeth R Goy, ${ }^{3}$ Jean Kutner, ${ }^{2}$ Miriam J Johnson, ${ }^{4}$ Janis M Miyasaki, ${ }^{5}$ Benzi Kluger ${ }^{6}$
}

\begin{abstract}
- Additional material is published online only. To view, please visit the journal online (http://dx.doi.org/10.1136/ jnnp-2020-323939).

${ }^{1}$ Neurology, Brown University Warren Alpert Medical School, Providence, Rhode Island, USA ${ }^{2}$ Department of Neurology, University of Colorado, Denver, Colorado, USA ${ }^{3}$ Department of Neurology, Portland VA Medical Center, Portland, Oregon, USA ${ }^{4}$ Department of Palliative Medicine, Hull York Medical School, Hull, UK

${ }^{5}$ Department of Neurology, University of Alberta, Edmonton, Alberta, Canada ${ }^{6}$ Department of Neurology, University of Rochester, Rochester, New York, USA
\end{abstract}

\section{Correspondence to} Dr Umer Akbar, Neurology, Brown University Warren Alpert Medical School, Providence, RI 02903, USA; umer_akbar@ brown.edu

UA and RBM contributed equally.

$U A$ and RBM are joint first authors.

Received 31 August 2020 Revised 10 January 2021 Accepted 12 January 2021 Published Online First 31 March 2021

\section{Check for updates}

(C) Author(s) (or their employer(s)) 2021. Re-use permitted under CC BY-NC. No commercial re-use. See rights and permissions. Published by BMJ.

To cite: Akbar U, McQueen RB, Bemski J, et al. J Neurol Neurosurg Psychiatry

2021:92:629-636.

\section{ABSTRACT}

Parkinson's disease and related disorders (PDRD) are the second most common neurodegenerative disease and a leading cause of death. However, patients with PDRD receive less end-of-life palliative care (hospice) than other illnesses, including other neurologic illnesses. Identification of predictors of PDRD mortality may aid in increasing appropriate and timely referrals. To systematically review the literature for causes of death and predictors of mortality in PDRD to provide guidance regarding hospice/end-of-life palliative care referrals. We searched MEDLINE, PubMed, EMBASE and CINAHL databases (1970-2020) of original quantitative research using patient-level, provider-level or caregiver-level data from medical records, administrative data or survey responses associated with mortality, prognosis or cause of death in PDRD. Findings were reviewed by an International Working Group on PD and Palliative Care supported by the Parkinson's Foundation. Of 1183 research articles, 42 studies met our inclusion criteria. We found four main domains of factors associated with mortality in PDRD: (1) demographic and clinical markers (age, sex, body mass index and comorbid illnesses), (2) motor dysfunction and global disability, (3) falls and infections and (4) non-motor symptoms. We provide suggestions for consideration of timing of hospice/endof-life palliative care referrals. Several clinical features of advancing disease may be useful in triggering end-of-life palliative/hospice referral. Prognostic studies focused on identifying when people with PDRD are nearing their final months of life are limited. There is further need for research in this area as well as policies that support need-based palliative care for the duration of PDRD.

\section{INTRODUCTION}

Parkinson's disease (PD) is the second most common neurodegenerative disorder, affecting more than $1 \%$ of adults over the age of 65 years and approximately 10 million people worldwide. ${ }^{1}$ With increasing access to specialist care coupled with improved diagnostic tools, a growing ageing population and prolonged survival due to better treatment options, the prevalence of PD is increasing and is expected to double by $2030 .^{2}$ The burden of PD and related disorders (PDRD), such as progressive supranuclear palsy (PSP), dementia with Lewy bodies, corticobasal degeneration and multiple system atrophy (MSA), is substantial and includes physical disability, ${ }^{3-8}$ dementia, ${ }^{5} 7$ 9-11 mood disorders, ${ }^{12} 13$ psychosis, ${ }^{14}$ increased mortality ${ }^{15-17}$ and financial hardship. ${ }^{15}$ Hospital admissions, duration of hospital stay and in-hospital mortality are higher among individuals with PDRD compared with patients with other lifelimiting conditions. ${ }^{16} 18-20$

The benefits of palliative care at end of life (hospice) and earlier in the disease course include improved quality of life, reduced healthcare expenditures and caregiver support. ${ }^{21} 22$ Benefits of earlier palliative care also have been demonstrated by a recent randomised controlled trial, in which patients receiving additional palliative care had better quality of life, symptom control, were more likely to have advanced care plans and better supported caregivers. ${ }^{23}$ Yet despite repeated calls for improved access, ${ }^{15} 24$ patients with PDRD spend less time in and are less likely to be referred to endof-life palliative care/hospice compared with other advanced diseases. Several studies suggest end-oflife palliative care/hospice is underused in PDRD, but estimates of use vary considerably, ranging from $0 \%$ (in a UK community sample) ${ }^{25}$ to $69 \%$ (in US nursing homes). ${ }^{162025-27}$ A multinational review of death certificate data from 2008 revealed that $0 \%$ of people with PDRD in New Zealand and 4\% in the USA died in hospice. ${ }^{20}$

In the USA, hospice care is defined as palliative care for persons with a 6-month life expectancy. Other nations differ in their definitions and criteria for receiving palliative care or hospice, with some based on prognosis and others on need. The Medicare hospice benefit in the USA is available to patients certified by two physicians to have a prognosis of 6 months or less and choose to focus medical care on comfort rather than life-extending treatments. ${ }^{28}$ Although PDRD is among the leading causes of death, there are no specific end-of-life palliative care/hospice eligibility guidelines for PDRD. Current guidelines potentially relevant to patients with PDRDs include those for dementia, amyotrophic lateral sclerosis (ALS; sometimes listed under the heading of generic neurologic disease) and adult failure to thrive (see table 1). ${ }^{29} 30$ The predictive value of these guidelines in PDRD has not been evaluated but are likely to be limited given: (a) a focus on clinical scenarios unlikely to be relevant in PDRD (eg, respiratory dysfunction); (b) lack of focus on clinical features of advanced PDRD and some common causes of death in this population (eg, falls) and (c) these guidelines are not sensitive 


\begin{tabular}{|c|c|}
\hline \multirow[t]{2}{*}{ Dementia } & 1. Stage $7 C$ or higher on the FAST Scale, AND \\
\hline & $\begin{array}{l}\text { 2. One or more of the following in the past year: aspiration pneumonia, pyelonephritis, septicemia, stage } 3 \text { or } 4 \text { pressure ulcers, recurrent fevers, other } \\
\text { conditions suggesting limited prognosis or inability to maintain sufficient fluid/caloric intake in past } 6 \text { months ( } 10 \% \text { weight loss or albumin }<2.5 \mathrm{~g} / \mathrm{dL} \text { ) }\end{array}$ \\
\hline \multirow[t]{2}{*}{ Stroke or coma } & 1. Palliative Performance Scale Score $\leq 40 \%$, AND \\
\hline & $\begin{array}{l}\text { 2. Poor nutritional status with inability to maintain sufficient fluid/caloric intake ( } 10 \% \text { weight loss in } 6 \text { months, } 7.5 \% \text { weight loss in } 3 \text { months, serum } \\
\text { albumin } \leq 2.5 \mathrm{~g} / \mathrm{dL} \text { or pulmonary aspiration resistant to speech therapy interventions) }\end{array}$ \\
\hline \multirow{4}{*}{$\begin{array}{l}\text { ALS (also listed as 'other } \\
\text { neurologic disease } \\
\text { including ALS, PD, MD, MG } \\
\text { or MS') }\end{array}$} & 1. Critically impaired breathing including dyspnoea at rest, vital capacity<30\%, oxygen need at rest and refusal of artificial ventilation, OR \\
\hline & 2. Rapid disease progression (to bed-bound status, unintelligible speech, need for pureed diet and/or major assistance needed for ADLs) with either: \\
\hline & $\begin{array}{l}\text {-A. Critical nutrition impairment in the prior year (inability to maintain sufficient fluid/caloric intake, continuing weight loss, dehydration and refusal of } \\
\text { artificial feeding methods), OR }\end{array}$ \\
\hline & $\begin{array}{l}\text {-B. Life-threatening complications in the prior year (recurrent aspiration pneumonia, pyelonephritis, sepsis, recurrent fever or stage } 3 \text { or } 4 \text { pressure } \\
\text { ulcers) }\end{array}$ \\
\hline \multirow[t]{2}{*}{ Generic } & 1. Terminal condition (can be multiple conditions), AND \\
\hline & $\begin{array}{l}\text { 2. Rapid decline over past } 3-6 \text { months as evidenced by progression of disease signs, symptoms and test results, decline in PPS } \leq 40 \% \text {, involuntary } \\
\text { weight loss }>10 \% \text { and/or albumin }<2.5 \mathrm{~g} / \mathrm{dL}\end{array}$ \\
\hline
\end{tabular}

ADL, activities of daily living; ALS, amyotrophic lateral sclerosis; FAST, Functional Assessment Staging Test; MD, muscular dystrophy; MG, myasthenia gravis; MS, multiple sclerosis; PD, Parkinson disease; PPS, Palliative Performance Scale.

even in the populations for which they were designed. ${ }^{31}$ Moreover, the lack of PDRD-specific guidelines may contribute to the impression that PDRD is not a cause of death or that death in PDRD is not predictable. In the UK, the National Institute for Health and Care Excellence (NICE) guidelines for PD do include recommendations relating to palliative care services based on clinical need rather than estimated prognosis. ${ }^{32}$ However, referrals to UK specialist palliative care services remain predominantly those with cancer, especially for in-patient services where only 10\% had neurological disease (2014-2015), although referrals for those with non-malignant disease, especially cardiorespiratory disease, is increasing.

Identification of events, symptoms and other characteristics of PDRD predicting mortality may aid in triggering timely and appropriate referral to end-of-life palliative care/hospice. ${ }^{21} 33$ While some mortality-associated factors in this population are known, there is little differentiation between general predictors of overall 'poor prognosis' versus specific predictors to suggest that an individual is in the last few weeks or months of life. Further, there has been no examination of whether a focus on predicting poor survival is fit for purpose with regard to increasing access to timely hospice referral.

This manuscript arose from a Parkinson's Foundation sponsored working group on PDRD and palliative care which identified improved hospice prediction as a high priority area. ${ }^{34}$ As a first step, we performed a thorough review of predictors of mortality and causes of death in PDRD to assess whether this approach would be of use in developing PDRD-specific guidance to inform timing of end-of-life palliative care/hospice referrals.

\section{METHODS}

\section{Search strategy}

We used the Preferred Reporting Items for Systematic Reviews and Meta-Analyses (PRISMA) checklist to inform our search strategy and reporting of outcomes. ${ }^{35}$ We conducted a database search using MEDLINE, PubMed, EMBASE and CINAHL in February 2020 and included publications from January 1970 up until that time. We also searched Google Scholar and the bibliographies of retrieved articles. Search terms combined Parkinson's disease, parkinsonism, progressive supranuclear palsy, dementia with Lewy bodies, corticobasal degeneration and multiple system atrophy with the following terms: Hospice; Palliative; Predictors; Prognosis; Mortality; place of death and cause of death.

\section{Inclusion criteria}

We included studies quantifying predictors of mortality and cause of death in patients with PDRD that met the following criteria: original research with quantitative data using patientlevel, provider-level or caregiver-level data from medical records, administrative data or survey responses and original research that predicted mortality or cause of death in patients with PDRD.

\section{Data abstraction and risk assessment}

Any two of three investigators (UA, JB and RBM) independently screened titles, abstracts and retrieved full papers with eligibility criteria. Differences were resolved by review of the third investigator.

We assessed risk of bias by reviewing study design characteristics, including appropriate temporal relationships between exposures and outcomes, matching populations through individual variables or propensity scores and other adjustment methods. However, given we did not develop a meta-analysis from the findings, we did not exclude reporting any studies that met our inclusion criteria.

\section{Outcomes}

The primary outcomes were overall quantitative predictors of mortality and predictors of mortality 6 months prior to death in patients with PDRD. Unadjusted and adjusted measures of association between PDRD predictors and mortality included mean differences with SD, relative risks (RRs), OR and HRs. Cause of death was quantified as percentage of patients by cause of death and standardised mortality ratios (SMRs).

\section{RESULTS}

Figure 1 and the online e-supplemental delineate the selection process.

\section{Study designs and descriptions of included studies}

The 42 studies were published until February 2020. The study designs were: retrospective cohort studies, ${ }^{3} 467101416172136-41$ prospective cohort and longitudinal studies, $589111342-49$ casecontrol studies ${ }^{50-54}$ and cross-sectional studies. ${ }^{125-60}$ Predictors of mortality included demographic and clinical markers, medical events, medication changes, disease-specific symptoms and 


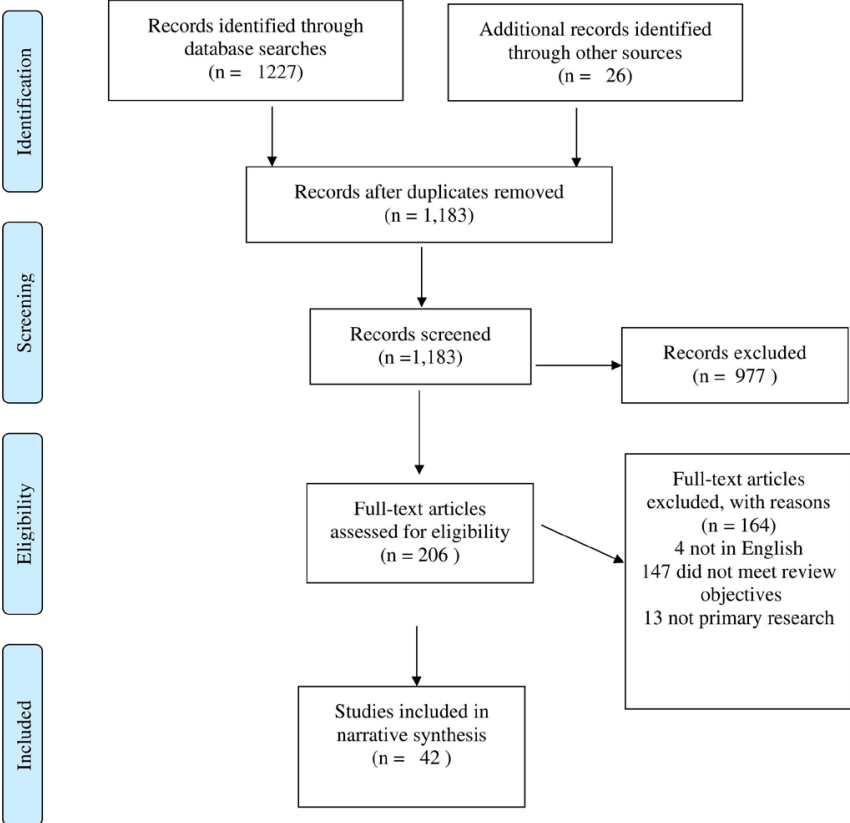

Figure 1 Preferred Reporting Items for Systematic Reviews and MetaAnalyses flow diagram.

patient and caregiver's ratings of health-related quality of life. Eight studies described both predictors of mortality and causes of death. ${ }^{373843-465361}$

\section{Demographic and general health measures}

Baseline demographic and general health predictors of mortality included age at onset or diagnosis, chronological age, male sex, body mass index (BMI) and comorbid illness. For every year increase in age at onset, there was an associated increase in a range of HRs from a minimum 1.05 (95\% CI: 1.01 to 1.10 ) to a maximum 1.11 (95\% CI: 1.09 to 1.12 ), with age ranging from 61 to 77 years of age at baseline for those who died. 359113742454652 Multiple analyses estimated the impact of 10 -year increases in age at onset on mortality, with increased HRs of 1.4 ( $p$ value $=0.023$ ) to 2.8 (95\% CI: 2.4 to 3.3). ${ }^{3947486162}$ Advanced chronological age or age at onset was estimated using a variety of methods, but in general found that patients with PDRD faced higher risk of death above 78-85 years of age at onset. ${ }^{6} 1043$ Male sex was associated with statistically significant increased HRs of 1.36 (95\% CI: 1.02 to 1.81 ) up to 2.9 (95\% CI: 1.5 to 5.4) compared with females 3911173739464762 ; RR increase of mortality of 1.7 (95\% CI: 1.6 to 1.9$)^{10}$ and fivefold higher odds of death (OR: 5.2; 95\% CI: 1.2 to 22.9). ${ }^{13}$ In a retrospective repeated measures analysis, Goy et al found rapidly declining BMI was significantly associated with progression to death among patients with PDRD. ${ }^{21}$ A decrease in BMI was seen, from mean of 26 (95\% CI: 25.1 to 26.1$)$ at $30-36$ months to 24.6 (95\% CI: 24.1 to 25.1 ) at 6-12 months prior to death. Further, an absolute BMI $<18$ was a predictor of mortality. ${ }^{20}$

Comorbid illnesses associated with death included congestive heart failure, diabetes mellitus, pressure ulcers and cardiovascular disease. In a retrospective cohort study of 15237 PDRD nursing home residents over 65 years of age, Fernandez and Lapane found significant decrease in time to death (rate ratios) of 1.49 (95\% CI: 1.35 to 1.65 ), 1.22 (95\% CI: 1.11 to 1.35 ) and 1.24 (1.13-1.37) from comorbid congestive heart failure, diabetes mellitus and pressure ulcers, respectively. Although it was not shown to be a predictor of death, cardiovascular disease was cited as a primary or secondary cause of death among patients with PDRD in multiple studies. ${ }^{37} 3844-465861$ Two 20-year follow-up studies of patients with PDRD in Europe found the majority of deaths were caused by cardiovascular disease $(30 \%$ and $42 \%){ }^{3744}$ Other studies found cardiovascular disease was a common cause of death among patients with PDRD, ranging from $12 \%$ to $21 \%$ of all deaths among patients with PDRD. ${ }^{38} 40455861$

\section{Motor symptoms and global disability}

Motor symptoms, as measured using the Unified Parkinson's Disease Rating Scale (UPDRS), Hoehn and Yahr Scale (H\&Y) and the Progressive Supranuclear Palsy Rating Scale (PSPRS), were significant predictors of mortality in patients with PDRD. ${ }^{63} 64$ Beyer et al found higher mean UPDRS scores, 65 (SD: 24) versus 42 (SD: 23), suggesting that greater motor impairment predicted death. ${ }^{43}$ Studies with median follow-up times ranging from 4 to 8 years estimated the association of 10 -unit increases in baseline motor UPDRS Score on mortality and found statistically significant increased HRs for mortality of 1.17 (95\% CI: 1.01 to 1.36 ) up to 1.4 (95\% CI: 1.3 to 1.5 ) for each 10 -unit increase in UPDRS Score. ${ }^{39} 4162$ Baseline H\&Y staging was significantly higher among those who died (mean 3.5 (SD 1)) compared with those who survived $\left(2.5\right.$ (0.9)). ${ }^{43}$ Posada et al went further by splitting H\&Y into early and later progression stages at baseline as a predictor for mortality and found that HRs increased by stage, from 1.5 (95\% CI: 1.1 to 2.2) for H\&Y stages 1 and 2 to 2.3 (95\% CI: 1.5 to 3.6) for H\&Y stages 3-5, both compared with patients with no PD and after controlling for comorbidities and demographic characteristics. ${ }^{53}$ Oosterveld et al stratified UPDRS total motor scores by greater than or equal to 30 compared with less than 30 (mean score for cohort 24.4) and found an HR of 1.63 (95\% CI: 1.13 to 2.35$).{ }^{11}$ Chiu et al compared the association of PSPRS scores on mortality and found ${ }^{47}$ increased HRs of 1.96 (95\% CI: 1.07 to 3.58) for 35-48 on the PSPRS, 2.99 (95\% CI: 1.65 to 5.43) for $48-62$ and 8.55 (95\% CI: 4.5 to 16.3 ) for greater than 62 when compared with scores of $0-34$.

Higginson et al conducted a 1-year longitudinal study analysing changes in symptoms in 82 patients with PDRD including MSA and PSP. All patients at study entry were stages 3-5 H\&Y with over $60 \%$ of patients having a severe disability (indicated by $\mathrm{H} \& \mathrm{Y}$ ) and $30 \%$ being wheelchair bound or bedridden. Compared with PD, patients with PSP and MSA had more disability and were more likely to die in 1 year $(6 \%$ vs 47\%). Baseline mean (range) Palliative Outcomes Scale scores for PD were 13.7 (14.5-5.7), 11.9 (10.0-6.1) for patients with PSP and $14.3(16.0-4.5)$ for patients with MSA. ${ }^{13}$

Motor disability and functional impairment were significantly associated with increased risk of mortality. Compared with mild impairment, a more severe score on Activities of Daily Living (ADL) Scale was associated with an increased mortality RR of 1.8 (95\% CI: 1.5 to 2.1$).{ }^{10}$ Symmetry of motor signs at baseline was associated with an increased HR of 2.0 (95\% CI: 1.1 to $3.7) .5$ Presence of akinesia plus rigidity at onset was associated with an increased HR of 2.2 (95\% CI: 1.06 to 4.88$).{ }^{44}$

We found only one study examining shift in prescribing of dopaminergic medication as an association with mortality. Goy et al found a shift in prescribing occurred during the last 6-12 months of life, with the proportion of patients with $\leq 2$ dopaminergic medications increasing from 0.5 in $18-24$ months to 0.6 in 6-12 months prior to death. ${ }^{21}$ 


\section{Falls and infections}

In two studies, location of bone fractures from falls were associated with increased mortality with PDRD after controlling for comorbidities and other demographic and clinical factors: upper limb fracture OR: 1.7 (95\% CI: 1.4 to 2.2); lower limb fracture OR: 1.2 (95\% CI: 1.1 to 1.3 ) and hip fracture OR: 1.13 (95\% CI: 1.03 to 1.24$){ }^{4}$ Kempster et al found frequent falls antemortem were present in $35 \%$ of PDRD decedents, with falls preceding death by 4.1 years on average. Frequency and timing of falls preceding death varied by age at death, but majority of falls occurred in older patients ( $>70$ years) and were reported 3.2-5.2 years before death. ${ }^{59}$

Two studies found the same increase in hazards for one point increase in postural instability gait disorder (PIGD) scores using different scales: the Short Parkinson's Evaluation Scale/Scales for Outcomes in Parkinson's disease (SPES/SCOPA) (HR: 1.3; 95\% CI: 1.1 to 1.5$)^{9}$ and the Tinetti balance and gait assessment $^{65}$ (HR: 1.3 ; 95\% CI: 1.1 to 1.5 ). ${ }^{3}$ Four other studies did not specify diagnostic tools for PIGD but found a range of HRs from a minimum 1.48 (95\% CI: 1.01 to 2.18$)^{37}$ to a maximum 2.1 (95\% CI: 1.2 to 3.7$)^{42}$ compared with no PIGD. ${ }^{534246}$

Pneumonia is a common cause of death among patients with PDRD and occurs at a higher frequency than in patients without PDRD. ${ }^{384345465161}$ A study of 237 patients with PDRD with a mean of 32.5-year follow-up found pneumonia had a higher SMR $(3.5 ; 95 \%$ CI: 1.4 to 7.3$)$ than cerebrovascular disease (1.8; 95\% CI: 1.2 to 2.7$)$ and cardiovascular disease $(1.6 ; 95 \%$ CI: 1.2 to 2.0$).{ }^{46}$ Other studies found an $11 \%-23 \%$ likelihood of death from pneumonia among patients with PDRD compared with $8 \%-9 \%$ in control patients. ${ }^{40451}$ Lethbridge et al found that patients with PDRD were 1.83 (95\% CI: 1.58 to 2.08 ) times more likely to have pneumonia at the time of death, compared with controls. ${ }^{56}$ Fernandez and Lapane found the mortality rate ratio of 1.58 (95\% CI: 0.97 to 2.56) from aspiration pneumonia was highest among all other comorbidities among a sample of PDRD nursing home residents.

\section{Non-motor symptoms}

The most frequent significant non-motor disability predictors of mortality were dementia and psychotic symptoms. Dementia was largely diagnosed using the Diagnostic and Statistical Manual of Mental Disorders versions 4 and earlier. ${ }^{66}$ Dementia was associated with increased HRs ranging from 1.7 (95\% CI: 1.7 to 1.8) up to 5 (95\% CI: 2.1 to 3.7)..$^{1642525362}$ Dementia was listed as the most ${ }^{58}$ or second-most common ${ }^{59}$ clinical feature at death for postmortem patients with PDRD, with symptoms preceding death by 3.3 years on average. ${ }^{59}$ Lethbridge et al found that patients with PDRD were 2.5 (95\% CI: 2.2 to 2.9) times more likely on average to have dementia when dying with PDRD compared with age-sex-matched controls without PDRD. ${ }^{56}$ In a study analysing contributing causes of death among patients with PDRD in Italy and France, SMRs for dementia were 49 per 1000000 people in both countries, compared with death from pneumonia (34 in Italy and 39 in France). ${ }^{55}$ A long-term follow-up study found the percentage of surviving patients with dementia increased dramatically from $24 \%$ at baseline to over $80 \%$ at 20 -year follow-up. ${ }^{67}$ Multiple studies using various scales have reported HR of 2.7-3 with severe cognitive impairment. ${ }^{5968}$ Garcia-Ptacek et al found that compared with MiniMental Status Exam scores above 25, there were increased HRs for scores between 20-24, 10-19 and 0-9 of 1.45 (95\% CI: 1.32 to 1.58 ), 2.14 (95\% CI: 1.96 to 2.34 ) and 2.91 (95\% CI: 2.47 to 3.44$)$, respectively. ${ }^{17}$ Another study found severe cognitive impairment, defined using the Cognitive Performance Scale, increased risk of mortality compared with mild cognitive impairment of 1.5 (95\% CI 1.4 to 1.7$){ }^{10}$

Two studies defined hallucinations using the UPDRS I question 2 with a score $\geq 2$ and found increased HRs of $1.45(95 \%$ CI: 1.02 to 2.07$)^{62}$ and 2.1 (95\% CI: 1.3 to 3.2$)^{5}$ compared with no hallucinations. The SCOPA-Psychiatric Complications ${ }^{69}$ was used as an assessment tool for hallucinations in one study (ie, presence of hallucinations, illusions, paranoid ideation or altered dream phenomena over the past month) and found an increased HR of 2.6 (95\% CI: 1.1 to 5.9). ${ }^{9}$ Psychotic symptoms in PD have been shown to increase the risk of nursing home placement (RR 3.4, CI 2.9 to 3.9) and death (1.3, CI 1.2 to 1.5$)^{14}$ and were found to be the most frequent clinical feature at death (61\%), preceding death by 5.1 years on average. ${ }^{59}$

Studies differ about the prognostic value of inspiratory stridor in patients with MSA. An international consensus conference was convened in Bologna in 2017 to discuss definition, diagnosis, prognosis and treatment of stridor. ${ }^{70}$ The experts concluded that the effect of stridor on survival is uncertain, but early stridor presenting within 3 years of diagnosis of MSA may shorten survival, and that daytime stridor (during wakefulness) portends a worse prognosis than purely nocturnal stridor. Continuous positive airway pressure can improve stridor but its effect on survival is uncertain. Tracheostomy can improve stridor and may improve survival as well. ${ }^{70}$

Other non-motor complications significantly predictive of mortality included dysphagia, cognitive impairment without a formal dementia diagnosis, sleep disorders, autonomic symptoms and neurologic bladder disturbances. Dysphagia, defined as a score of $>1$ on UPDRS II question 3, was associated with an increased HR of 1.4 (95\% CI: 1.08 to 1.86$).^{5}$ In a study by dell'Aquila et al, early signs of dysphagia and cognitive decline ( $<3$ years from onset) among patients with PSP were associated with increased HRs of 2.3 (95\% CI: 1 to 5.3) and 3.6 (95\% CI: 1.6 to 8.2 ), respectively. ${ }^{48}$ Sleep disorders were associated with a RR increase of 1.3 (95\% CI: 1.2 to 1.6$)^{10}$ and an increased HR of 2.7 (95\% CI: 1.1 to 6.7 ) associated with rapid eye movement sleep behaviour disorder ${ }^{54}$ Finally, two studies found associations between urinary incontinence and mortality (statistics not reported) ${ }^{38}$ and incomplete bladder emptying (HR 2.10 (95\% CI 1.02 to 4.30$)){ }^{8}$ Early development of stridor in MSA, especially while awake, portends decreased survival. ${ }^{70} 71$

\section{DISCUSSION}

Patients with PDRD suffer from severe disease burden in advanced disease and may be less likely to be referred for hospice and/or palliative care services than other similarly burdensome disorders. Important findings from this systemic review include: (1) mortality is heightened in PDRD and complications of PDRD contribute to death; (2) general markers of health decline may predict mortality in PDRD; (3) disease-specific markers of advanced disease may predict mortality in PDRD and (4) predictors of death are linked to common causes of excess mortality in PDRD (eg, dysphagia and aspiration pneumonia). We found four main domains of mortality predictors or causes of death for PDRD (table 2).

1. Demographic and general health measures: Older age at disease onset, male sex, rapidly decreasing BMI and higher number-and especially cardiovascular-comorbidities are associated with higher mortality. Medication changes can occur at any stage of the disease, but decreasing medication when control of motor symptoms is outweighed by 
Table 2 Summary of predictors of mortality for Parkinson's and related disorders

\begin{tabular}{|c|c|c|c|}
\hline Domain & Description & Assessment & Reference \\
\hline \multirow{6}{*}{$\begin{array}{l}\text { Demographic and } \\
\text { clinical markers }\end{array}$} & Age at onset/duration of disease & $>61$ years of age at onset & 359113742454652 \\
\hline & Chronological age & $78-85$ years of age & 61043 \\
\hline & Sex & Male & $39-11173739464762$ \\
\hline & Body mass index (BMI) & $\begin{array}{l}\text { Accelerated decrease in BMI for patients with PD }(18.5-25 \mathrm{~kg} / \\
\left.\mathrm{m}^{2}\right)\end{array}$ & 21 \\
\hline & Comorbid illness & $\begin{array}{l}\text { Congestive heart failure, diabetes mellitus, pressure ulcers, } \\
\text { cardiovascular disease }\end{array}$ & $610373844-465861$ \\
\hline & Prescribing shift & $\begin{array}{l}\text { Shift to fewer dopaminergic medications from previous visits } \\
(\mathrm{ie}, \leq 2)\end{array}$ & 21 \\
\hline \multirow{6}{*}{$\begin{array}{l}\text { Motor symptoms and } \\
\text { global disability }\end{array}$} & Hoehn and Yahr Scale (H\&Y) & H\&Y stage increases (from stages $3-5$ at first assessment) & 4353 \\
\hline & Postural instability gait disorder & $\begin{array}{l}\text { Increase in scores from baseline as low as } 1 \text { unit on Tinetti } \\
\text { balance and gait assessment and SPES/SCOPA }\end{array}$ & 5937424665 \\
\hline & $\begin{array}{l}\text { Unified Parkinson's Disease Rating Scale } \\
\text { (UPDRS) }\end{array}$ & $\begin{array}{l}\text { Significant increases in overall UPDRS Score ( } \geq 10 \text { point } \\
\text { increase in total scale score over first assessment) }\end{array}$ & 1139414362 \\
\hline & Activities of daily living & Severe score ( 2 or less) & 10 \\
\hline & Palliative Outcomes Scale (POS) & $\begin{array}{l}\text { Upward trajectory of POS scores compared with first } \\
\text { assessment }\end{array}$ & 13 \\
\hline & $\begin{array}{l}\text { Progressive Supranuclear Palsy Rating } \\
\text { Scale (PSPRS) }\end{array}$ & Significant increases in PSPRS scores over 35 & 47 \\
\hline \multirow[t]{3}{*}{ Falls and infections } & Fracture risk & $\begin{array}{l}\text { Fractures in previous } 3-5 \text { years with attention to fracture site } \\
\text { (upper limb, lower limb, hip) }\end{array}$ & 460 \\
\hline & History of infections & Pneumonia diagnosis & 384043454651566061 \\
\hline & & Sepsis or urosepsis & 6 \\
\hline \multirow[t]{4}{*}{ Non-motor symptoms } & Dementia/cognitive impairment & $\begin{array}{l}\text { Diagnosis in medical record history using DSM classification; } \\
\text { MMSE Score } \leq 24 \text {; SCOPA-COG }<23 \text {; severe cognition from CPS }\end{array}$ & 5910161742525355565862 66-68 \\
\hline & Visual hallucinations; vision problems & $\begin{array}{l}\text { UPDRS I question } 2 \text { with a score } \geq 2 \text {; SCOPA-PC: presence in } \\
\text { past month of hallucinations, illusions, paranoid ideation or } \\
\text { altered dream phenomena; diagnosis if rapid eye movement } \\
\text { sleep behaviour disorder; }>2 \text { medical claims for psychosis }\end{array}$ & 59101454596269 \\
\hline & Dysphagia & $\begin{array}{l}\text { UPDRS II question } 3 \text { with a score } \geq 2 \text { and correlated with clinical } \\
\text { assessment; survey of caretakers }\end{array}$ & 560 \\
\hline & $\begin{array}{l}\text { Neurologic bladder disturbances } \\
\text { Stridor (in MSA) }\end{array}$ & $\begin{array}{l}\text { Incontinence and incomplete bladder emptying } \\
\text { Clinical observation; laryngoscopy }\end{array}$ & 83870 \\
\hline
\end{tabular}

DSM, Diagnostic and Statistical Manual; MMSE, Mini-Mental Status Exam; ${ }_{i}^{80}$ SPES/SCOPA, Short Parkinson's Evaluation Scale/Scales for Outcomes in Parkinson's disease; ${ }^{81}$ SCOPA-PC, SCOPA-Psychiatric Complications; ${ }_{i}^{69}$ SCOPA-COG, SCOPA-Cognition; ${ }^{82}$ CPS, Cognitive Performance Scale. ${ }^{83}$

MSA, multiple system atrophy; PD, Parkinson's disease.

the disability caused by the cumulative burden of disease has been associated with death within 6-12 months.

2. Motor dysfunction and global disability: More severe motor symptoms and worse performance on ADL scales is associated with global disability and mortality. Motor signs presenting symmetrically, presence of akinesia/rigidity and the PIGD subtype were all associated with increased mortality.

3. Falls and infections: Bone fractures and their locations are associated with increased mortality, but may precede death by months to years. Aspiration pneumonia is a common occurrence in advanced disease, and recurrent pneumonia portends poor short-term prognosis (months).

4. Non-motor symptoms: Cognitive dysfunction, specifically dementia and psychotic symptoms are the most common non-motor features present prior to death in PDRD. Other reported non-motor features associated with mortality include dysphagia, sleep disorders, autonomic symptoms, stridor and neurologic bladder disturbances.

\section{Potential barriers to hospice and palliative care referral}

Although palliative and end-of-life care for PDRD is attracting increased attention, there remain many barriers to improving care including clinician discomfort, poor integration and coordination of palliative care within neurology, misperception of the potential for death from PDRD and patient misperception of palliative and hospice care. ${ }^{72}$ Notably, caregivers of PDRD decedents indicated that physicians rarely discussed end-of-life expectations and that the caregiver usually initiated such discussions. ${ }^{60}$ The unpredictability of the disease trajectory, especially at end of life, and how to address this uncertainty with patients may hinder these discussion. In addition, patients with PDRD may have clinical plateaus at very low levels of function which may lead to inappropriate discharges from palliative care or hospice, particularly in medical systems where end-of-life palliative care services are tied to prognosis and disease progression. Where the system operates as mutually exclusive, admission to hospice care, due to the waxing-waning course the patient may be discharged from hospice 'comfort' care to seek 'curative' care, a practice that is driven by three main factors: physician perception, patient/family preference and stability/improvement of medical condition. $^{73} \mathrm{~A}$ study of national live discharges from hospice ${ }^{74}$ found that one in four discharged patients were hospitalised within the following 30 days, $75 \%$ were admitted within 1 day of discharge and 34\% of them died within 30 days of hospice discharge. ${ }^{74}$ Other system issues, such as restrictions on care for persons receiving hospice, such as exclusion of physical therapy services that may still be beneficial to patients with PDRD with advanced illness, may lead to inappropriate underutilisation of 
these services and could contribute to misperceptions that all palliative care is incompatible with disease-targeted treatments. In addition, in healthcare systems such as in the UK, many hospice services are charity, rather than state, funded and arose out of oncology palliative care and some still may not accept patients with neurological illness.

\section{Mortality assessment tools}

In the USA, hospice referral is predicated on the risk of mortality and estimation of time to death, which differs from other nations that base hospice/end-of-life palliative care on need rather than prognosis. Currently, there are no PDRD-specific hospice/endof-life palliative care referral guidelines in the USA, and the closest potentially relevant Medicare guidelines to PDRD are for dementia, failure to thrive or 'other neurological diseases' which include ALS, myasthenia gravis and multiple sclerosis. These guidelines have poor predictive power of mortality and more sensitive and specific tools have been developed. For example, the Minimum Data Set-Changes in Health, End-stage disease and Symptoms and Signs (MDS-CHESS) Score ${ }^{75} 76$ (range 0-5) was developed to predict mortality in the frail, elderly nursing home population. Of the nursing home residents with CHESS Score of 5, 95\% died within 2 years, compared with $24 \%$ of those admitted with a baseline score of $0 .^{76}$ The CHESS Score was found to be a valid predictor of 6-month mortality among Canadians with 1 of 11 neurological diagnoses, including PDRD. ${ }^{77}$ Mitchell et al used the MDS to develop the Advanced Dementia Prognostic Tool (ADEPT) ${ }^{78}$ which was designed to predict 6-month mortality in nursing home dementia patients. The 6-month mortality rate increased across risk scores (possible range, $0-19$ ): 0 points, $8.9 \%$ mortality; $1-2,10.8 \%$ mortality; 3-5, 23.2\% mortality; 6-8, 40.4\% mortality; 9-11, $57.0 \%$ mortality and at least $12,70.0 \%$ mortality in the validation cohort. The area under the receiver operating curve for predicting 6-month mortality was 0.74 and 0.70 in the derivation and validation cohorts, respectively. ${ }^{78}$

Although these and other prognostic tools have improved predictive power, still they share the disadvantage of lacking specificity for the PDRD population. Given that PDRD are notoriously variable in presentation, progression and symptom burden in the last months of life, guidelines for other neurological diseases may be unsuitable for people with PDRD. Nonetheless, in the absence of more specific prognostic tools for PDRD, we suggest that clinicians should consider current Medicare hospice eligibility criteria, the MDS-CHESS tool or the ADEPT to consider whether an individual may benefit from hospice and/ or palliative care referrals. Of note, the NICE guidance in the
UK has opted to place the emphasis on the needs of the patient rather than the likely proximity to death.

\section{Expert guidance and recommendations for end-of-life palliative care/hospice referrals}

Based on this review, we provide recommendations for providers on identifying patients with PDRD—who may be nearing end of life-for hospice (end-of-life palliative care) referral in table 3 . These recommendations include patients exhibiting (1) evidence of advanced disease, or (2) rapid or accelerated disease progression, or (3) advanced dementia. These guidelines differ from current Medicare guidelines in that they are specifically targeted for PDRD and have expanded hospice/end-of-life palliative care triggers to include falls with fractures, loss of efficacy of medications and cover both motor and non-motor symptoms. We have also added that rapid or accelerated decline should trigger consideration for hospice/end-of-life palliative care in that our collective experience suggests that decline rarely follows a straight line and often accelerates as patients are nearing the end of life. Even when patients may not be appropriate for services which are limited by prognosis (eg, hospice in the USA), these guidelines may be used as event triggers for goals of care discussions, anticipatory guidance for patients and families and suggest areas for clinical monitoring (eg, nutrition) that are often not emphasised with current standards of care. ${ }^{79}$ It is worthy of note that atypical parkinsonian conditions may merit earlier palliative care. However, there is currently no sufficient evidence to suggest that triggers for hospice would be different, and it is our experience that patients with advanced PDRD have similar predictors of the terminal phase.

These guidelines are perhaps better placed in terms of being used to identify the patient who is likely to have needs which could be benefited by referral to hospice/palliative care, rather than who is likely to die within a certain timeframe. This obviates the need to have robust predictors of mortality, instead, it re-frames the issue in terms of the need to have robust predictors of clinical need. This frees the referrer from having to be sure that the patient should now stop disease management and change to palliation alone. It also frees the clinician and patient from the anomaly of needing to choose between the two approaches, when ongoing optimisation of PDRD disease management is a cornerstone of excellent palliation.

For clinicians caring for this population, we recommend that this guidance be used and specifically cited when making hospice/ palliative care referrals and framed in terms of need. Other data reviewed in this paper can also be used in one's clinical documentation to further support hospice referral where the healthcare

Table 3 Suggested hospice guidance for Parkinson's disease and related disorders, one of the following three criteria are required

1. Demonstrates evidence of advanced disease as manifested by either $A, B$ or $C$ criteria A. Critical nutrition impairment in the prior year (inability to maintain sufficient fluid/ caloric intake and dehydration, or BMl<18, or $10 \%$ weight loss over 6 months and refusal of artificial feeding methods); or

B. Life-threatening complications in the prior year (recurrent aspiration pneumonia, falls with fractures, pyelonephritis, sepsis, recurrent fever or stage 3 or 4 pressure ulcers); or

C. Motor symptoms that are poorly responsive to dopaminergic medications or which cannot be treated with dopaminergic medications due to unacceptable side effects and result in significant impairments in ability to perform self-care, or

2. Rapid or accelerating motor dysfunction (including gait and balance) or non-motor disease progression (including severe dementia, dysphagia, bladder dysfunction, stridor (in MSA)) and disability (restricted to bed or chair bound status, unintelligible speech, need for pureed diet and/or major assistance needed for ADLs), or

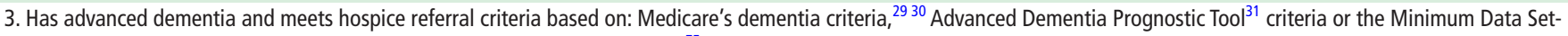
Changes in Health, End-stage disease and Symptoms and Signs Score criteria. ${ }^{75}$

ADLs, activities of daily living; BMI, body mass index; MSA, multiple system atrophy. 
system requires an estimation of prognosis. This could include mentioning that a patient's age, gender or comorbid illnesses place him/her at higher risk for death in the ensuing 6 months. We would like to emphasise that the determination of mortality risk estimates ultimately rests on the referring and hospice clinicians and that our recommendations and Medicare guidelines are not requisite criteria. We also suggest that discussions regarding hospice/end-of-life palliative care begin with goals of care and how the services provided by hospice may support those goals rather than focusing on prognosis which, even with the best of guidelines, is an inexact science. Access to hospice services based on a problem-based approach informed, but not dictated, by prognostic information would allow intermittent, as necessary, access to services skilled in supporting complex and persistent symptoms and other concerns in a timely manner.

\section{Limitations}

While we performed a rigorous search and followed PRISMA guidelines, there are limitations to our systematic review. We did not include every database in our search and excluded nonEnglish papers. Additionally, in order to present the full extent of the knowledge available in this area, quality assessment was not conducted because: (1) only limited data are available in this field, (2) restricting inclusion criteria would further decrease the quantity of publications and (3) strict exclusion may have led to inclusion only of certain papers with significant bias. Further attempts are needed to both assess quality and conduct a metaanalysis to combine these quantitative predictors. We also recognise that end-of-life hospice care may also be defined as palliative care depending on country-specific definitions. Majority of the studies evaluated in this review included patients with PD, while only a few studies included patients with other parkinsonian disorders. Lastly, we acknowledge that the proposed recommendations presented here are likely to evolve as more, highquality research becomes available, but this, we believe, is a good starting point.

\section{CONCLUSIONS AND FUTURE DIRECTIONS}

The strength of this review is the systematic approach we followed including involvement of an international working group with expertise in palliative care and movement disorders. Further research is needed to determine the effectiveness of these recommendations in terms of maximising remaining quality of life by allowing patients with PDRD access to timely palliative care and hospice services based on clinical need and not estimated survival alone. An integrated approach to palliation and disease-directed management would remove the eligibility requirement of a short prognosis allowing both aspects of care to contribute to the patient living as well as they can for as long as they can.

Contributors Planning/idea: ERG, JK, MJJ, JMM and BK. Conducting review/ manuscript preparation: UA, RBM, JB and BK. Critical review of the manuscript: UA, RBM, JC, ERG, JK, MJJ, JMM and BK. Guarantors: UA and BK (accept full responsibility for the work).

Funding Support for this study includes 2015 Parkinson's Foundation Conference grant for International Working Group on Palliative Care and Parkinson's Disease.

Competing interests None declared.

Patient consent for publication Not required.

Provenance and peer review Commissioned; externally peer reviewed.

Supplemental material This content has been supplied by the author(s). It has not been vetted by BMJ Publishing Group Limited (BMJ) and may not have been peer-reviewed. Any opinions or recommendations discussed are solely those of the author(s) and are not endorsed by BMJ. BMJ disclaims all liability and responsibility arising from any reliance placed on the content. Where the content includes any translated material, BMJ does not warrant the accuracy and reliability of the translations (including but not limited to local regulations, clinical guidelines, terminology, drug names and drug dosages), and is not responsible for any error and/or omissions arising from translation and adaptation or otherwise.

Open access This is an open access article distributed in accordance with the Creative Commons Attribution Non Commercial (CC BY-NC 4.0) license, which permits others to distribute, remix, adapt, build upon this work non-commercially, and license their derivative works on different terms, provided the original work is properly cited, appropriate credit is given, any changes made indicated, and the use is non-commercial. See: http://creativecommons.org/licenses/by-nc/4.0/.

\section{ORCID iD}

Umer Akbar http://orcid.org/0000-0003-1443-7513

\section{REFERENCES}

1 What is Parkinson's Disease [online]. Available: http://www.pdf.org/about_pd

2 Pringsheim T, Jette N, Frolkis A, et al. The prevalence of Parkinson's disease: a systematic review and meta-analysis. Mov Disord 2014;29:1583-90.

3 Gray WK, Hildreth A, Bilclough JA, et al. Physical assessment as a predictor of mortality in people with Parkinson's disease: a study over 7 years. Mov Disord 2009;24:1934-40.

4 Huang Y-F, Cherng Y-G, Hsu SPC, et al. Risk and adverse outcomes of fractures in patients with Parkinson's disease: two nationwide studies. Osteoporos Int 2015;26:1723-32.

5 Lo RY, Tanner CM, Albers KB, et al. Clinical features in early Parkinson disease and survival. Arch Neurol 2009;66:1353-8.

6 Manabe T, Mizukami K, Akatsu H, et al. Prognostic factors related to dementia with Lewy bodies complicated with pneumonia: an autopsy study. Intern Med 2016;55:2771-6.

7 O'Sullivan SS, Massey LA, Williams DR, et al. Clinical outcomes of progressive supranuclear palsy and multiple system atrophy. Brain 2008;131:1362-72.

8 Wenning GK, Geser F, Krismer F, et al. The natural history of multiple system atrophy: a prospective European cohort study. Lancet Neurol 2013;12:264-74.

9 de Lau LML, Verbaan D, Marinus J, et al. Survival in Parkinson's disease. relation with motor and non-motor features. Parkinsonism Relat Disord 2014;20:613-6.

10 Fernandez HH, Lapane KL. Predictors of mortality among nursing home residents with a diagnosis of Parkinson's disease. Med Sci Monit 2002;8:Cr241-6.

11 Oosterveld LP, Allen JC, Reinoso G, et al. Prognostic factors for early mortality in Parkinson's disease. Parkinsonism Relat Disord 2015;21:226-30.

12 Goy ER, Carter JH, Ganzini L. Parkinson disease at the end of life: caregiver perspectives. Neurology 2007;69:611-2.

13 Higginson IJ, Gao W, Saleem TZ, et al. Symptoms and quality of life in late stage Parkinson syndromes: a longitudinal community study of predictive factors. PLoS One 2012;7:e46327.

14 Wetmore JB, Li S, Yan H, et al. Increases in institutionalization, healthcare resource utilization, and mortality risk associated with Parkinson disease psychosis: retrospective cohort study. Parkinsonism Relat Disord 2019;68:95-101.

15 Miyasaki JM, Kluger B. Palliative care for Parkinson's disease: has the time come? Curr Neurol Neurosci Rep 2015;15:26

16 Willis AW, Schootman $M$, Kung $N$, et al. Predictors of survival in patients with Parkinson disease. Arch Neurol 2012;69:601-7.

17 Garcia-Ptacek S, Farahmand B, Kåreholt I, et al. Mortality risk after dementia diagnosis by dementia type and underlying factors: a cohort of 15,209 patients based on the Swedish dementia registry. J Alzheimers Dis 2014;41:467-77.

18 Guttman M, Slaughter PM, Theriault M-E, et al. Burden of parkinsonism: a populationbased study. Mov Disord 2003;18:313-9.

19 Low V, Ben-Shlomo Y, Coward E, et al. Measuring the burden and mortality of hospitalisation in Parkinson's disease: a cross-sectional analysis of the English Hospital episodes statistics database 2009-2013. Parkinsonism Relat Disord 2015:21:449-54.

20 Moens K, Houttekier D, Van den Block L, et al. Place of death of people living with Parkinson's disease: a population-level study in 11 countries. BMC Palliat Care 2015; $14: 28$

21 Goy ER, Bohlig A, Carter J, et al. Identifying predictors of hospice eligibility in patients with Parkinson disease. Am J Hosp Palliat Care 2015;32:29-33.

22 Kirolos I, Tamariz L, Schultz EA, et al. Interventions to improve hospice and palliative care referral: a systematic review. J Palliat Med 2014;17:957-64.

23 Kluger BM, Miyasaki J, Katz M, et al. Comparison of integrated outpatient palliative care with standard care in patients with Parkinson disease and related disorders: a randomized clinical trial. JAMA Neurol 2020;77:551-60.

24 Miyasaki JM. Palliative care in Parkinson's disease. Curr Neurol Neurosci Rep 2013;13:367.

25 Snell K, Pennington S, Lee M, et al. The place of death in Parkinson's disease. Age Ageing 2009;38:617-9 
26 Mantri S, Fullard ME, Beck J, et al. State-level prevalence, health service use, and spending vary widely among Medicare beneficiaries with Parkinson disease. NPJ Parkinsons Dis 2019:5:1-9.

27 Safarpour D, Thibault DP, DeSanto CL, et al. Nursing home and end-of-life care in Parkinson disease. Neurology 2015;85:413-9.

28 U.S. Department of Health and Human Services Health Care Financing. Medicare hospice benefits, 2016.

29 Boersma I, Miyasaki J, Kutner J, et al. Palliative care and neurology: time for a paradigm shift. Neurology 2014;83:561-7.

30 U.S. Department of Health and Human Services Health Care Financing. Medicare Hospice Benefits [online]. Available: http://www.medicare.gov/Publications/Pubs/pdf/ 02154.pdf

31 Mitchell SL, Miller SC, Teno JM, et al. The advanced dementia prognostic tool: a risk score to estimate survival in nursing home residents with advanced dementia. J Pain Symptom Manage 2010;40:639-51.

32 Parkinson's disease: summary of updated NICE guidance. BMJ 2019;364:1961.

33 Richfield EW, Jones EJS, Alty JE. Palliative care for Parkinson's disease: a summary of the evidence and future directions. Palliat Med 2013;27:805-10.

34 Kluger BM, Fox S, Timmons S, et al. Palliative care and Parkinson's disease: meeting summary and recommendations for clinical research. Parkinsonism Relat Disord 2017;37:19-26.

35 Moher D, Liberati A, Tetzlaff J, et al. Preferred reporting items for systematic reviews and meta-analyses: the PRISMA statement. Int J Surg 2010;8:336-41.

36 Allyson Jones C, Wayne Martin WR, Wieler M, et al. Incidence and mortality of Parkinson's disease in older Canadians. Parkinsonism Relat Disord 2012;18:327-31.

37 Diem-Zangerl A, Seppi K, Wenning GK, et al. Mortality in Parkinson's disease: a 20year follow-up study. Mov Disord 2009;24:819-25.

38 Litvan I, Mangone CA, McKee A, et al. Natural history of progressive supranuclear palsy (Steele-Richardson-Olszewski syndrome) and clinical predictors of survival: a clinicopathological study. J Neurol Neurosurg Psychiatry 1996;60:615-20.

39 Marras C, McDermott MP, Rochon PA, et al. Survival in Parkinson disease: Thirteenyear follow-up of the DATATOP cohort. Neurology 2005;64:87-93.

40 Pennington S, Snell K, Lee M, et al. The cause of death in idiopathic Parkinson's disease. Parkinsonism Relat Disord 2010;16:434-7.

41 Vu TC, Nutt JG, Holford NHG. Disease progress and response to treatment as predictors of survival, disability, cognitive impairment and depression in Parkinson's disease. Br J Clin Pharmacol 2012;74:284-95.

42 Auyeung M, Tsoi TH, Mok V, et al. Ten year survival and outcomes in a prospective cohort of new onset Chinese Parkinson's disease patients. J Neurol Neurosurg Psychiatry 2012;83:607-11.

43 Beyer MK, Herlofson K, Årsland D, et al. Causes of death in a community-based study of Parkinson's disease. Acta Neurol Scand 2001;103:7-11.

44 Duarte J, García Olmos LM, Mendoza A, et al. The natural history of Parkinson's disease in the province of Segovia: mortality in a longitudinal study (20-year followup). Acta Neurol Scand 2013;127:295-300

45 Fernandes GC, Socal MP, Schuh AFS, et al. Clinical and epidemiological factors associated with mortality in Parkinson's disease in a Brazilian cohort. Parkinsons Dis 2015;2015:959304

46 Pinter B, Diem-Zangerl A, Wenning GK, et al. Mortality in Parkinson's disease: a 38year follow-up study. Mov Disord 2015;30:266-9.

47 Chiu WZ, Kaat LD, Seelaar H, et al. Survival in progressive supranuclear palsy and frontotemporal dementia. J Neurol Neurosurg Psychiatry 2010;81:441-5.

48 dell'Aquila C, Zoccolella S, Cardinali V, et al. Predictors of survival in a series of clinically diagnosed progressive supranuclear palsy patients. Parkinsonism Relat Disord 2013;19:980-5.

49 Nath U, Ben-Shlomo Y, Thomson RG, et al. Clinical features and natural history of progressive supranuclear palsy: a clinical cohort study. Neurology 2003;60:910-6.

50 Elbaz A, Bower JH, Peterson BJ, et al. Survival study of Parkinson disease in Olmsted County, Minnesota. Arch Neurol 2003:60:91-6.

51 Fall P-A, Saleh A, Fredrickson M, et al. Survival time, mortality, and cause of death in elderly patients with Parkinson's disease: a 9-year follow-up. Mov Disord 2003;18:1312-6.

52 Hughes TA, Ross HF, Mindham RHS, et al. Mortality in Parkinson's disease and its association with dementia and depression. Acta Neurol Scand 2004;110:118-23.

53 Posada IJ, Benito-León J, Louis ED, et al. Mortality from Parkinson's disease: a population-based prospective study (NEDICES). Mov Disord 2011;26:2522-9.

$54 \mathrm{Wu}$ Y-H, Lee W-J, Chen Y-H, et al. Premotor symptoms as predictors of outcome in Parkinsons disease: a case-control study. PLoS One 2016:11:e0161271.

55 Désesquelles A, Demuru E, Salvatore MA, et al. Mortality from Alzheimer's disease, Parkinson's disease, and dementias in France and Italy: a comparison using the multiple cause-of-death approach. J Aging Health 2014;26:283-315.
56 Lethbridge L, Johnston GM, Turnbull G. Co-morbidities of persons dying of Parkinson's disease. Prog Palliat Care 2013;21:140-5.

57 Nath Uet al. Population based mortality and quality of death certification in progressive supranuclear palsy (Steele-Richardson-Olszewski syndrome). J Neurol Neurosurg Psych 2005;76:498-502

58 Tuck KK, Zive DM, Schmidt TA, et al. Life-sustaining treatment orders, location of death and co-morbid conditions in decedents with Parkinson's disease. Parkinsonism Relat Disord 2015:21:1205-9.

59 Kempster PA, O'Sullivan SS, Holton JL, et al. Relationships between age and late progression of Parkinson's disease: a clinico-pathological study. Brain 2010;133:1755-62.

60 Armstrong MJ, Alliance S, Corsentino P, et al. Cause of death and end-of-life experiences in individuals with dementia with Lewy bodies. J Am Geriatr Soc 2019;67:67-73.

61 Hely MA, Morris JGL, Traficante R, et al. The Sydney multicentre study of Parkinson's disease: progression and mortality at 10 years. J Neurol Neurosurg Psych 1999;67:300-7.

62 Forsaa EB, Larsen JP, Wentzel-Larsen T, et al. What predicts mortality in Parkinson disease?: a prospective population-based long-term study. Neurology 2010;75:1270-6.

63 Hoehn MM, Yahr MD. Parkinsonism: onset, progression and mortality. Neurology 1967:17:427-42.

64 Palmer JL, Coats MA, Roe CM, et al. Unified Parkinson's disease rating Scale-Motor exam: inter-rater reliability of advanced practice nurse and neurologist assessments. $J$ Adv Nurs 2010;66:1382-7

65 Tinetti ME. Performance-oriented assessment of mobility problems in elderly patients. J Am Geriatr Soc 1986;34:119-26.

66 American Psychiatric Pub. Diagnostic and statistical manual of mental disorders (DSM-5尺). American Psychiatric Pub, 2013.

67 Reid WGJ, Hely MA, Morris JGL, et al. Dementia in Parkinson's disease: a 20-year neuropsychological study (Sydney multicentre study). J Neurol Neurosurg Psychiatry 2011;82:1033-7.

68 Verbaan D, Marinus J, Visser M, et al. Cognitive impairment in Parkinson's disease. J Neurol Neurosurg Psych 2007;78:1182-7.

69 Visser M, Verbaan D, van Rooden SM, et al. Assessment of psychiatric complications in Parkinson's disease: the SCOPA-PC. Mov Disord 2007;22:2221-8.

70 Cortelli P, Calandra-Buonaura G, Benarroch EE, et al. Stridor in multiple system atrophy: consensus statement on diagnosis, prognosis, and treatment. Neurology 2019:93:630-9.

71 Silber MH, Levine S. Stridor and death in multiple system atrophy. Mov Disord 2000;15:699-704

72 Fox S, Cashell A, Kernohan WG, et al. Interviews with Irish healthcare workers from different disciplines about palliative care for people with Parkinson's disease: a definite role but uncertainty around terminology and timing. BMC Palliat Care 2016;15:15

73 Kutner JS, Meyer SA, Beaty BL, et al. Outcomes and characteristics of patients discharged alive from hospice. J Am Geriatr Soc 2004;52:1337-42.

74 Teno JM, Plotzke M, Gozalo P, et al. A national study of live discharges from hospice. J Palliat Med 2014;17:1121-7

75 Hirdes JP, Frijters DH, Teare GF. The MDS-CHESS scale: a new measure to predict mortality in institutionalized older people. J Am Geriatr Soc 2003;51:96-100.

76 Ogarek JA, McCreedy EM, Thomas KS, et al. Minimum data set changes in health, end-stage disease and symptoms and signs scale: a revised measure to predict mortality in nursing home residents. J Am Geriatr Soc 2018;66:976-81.

77 Hirdes JP, Poss JW, Mitchell $L$, et al. Use of the interRAI chess scale to predict mortality among persons with neurological conditions in three care settings. PLOS One 2014;9:e99066.

78 Mitchell SL, Kiely DK, Hamel MB, et al. Estimating prognosis for nursing home residents with advanced dementia. JAMA 2004:291:2734-40.

79 Creutzfeldt CJ, Robinson MT, Holloway RG. Neurologists as primary palliative care providers: communication and practice approaches. Neurol Clin Pract 2016:6:40-8.

80 Folstein MF, Folstein SE, McHugh PR. "Mini-mental state". A practical method for grading the cognitive state of patients for the clinician. J Psychiatr Res 1975; 12:189-98.

81 Marinus Jet al. A short scale for the assessment of motor impairments and disabilities in Parkinson's disease: the SPES/SCOPA. J Neurol Neurosurg Psych 2004;75:388-95.

82 Marinus J, Visser M, Verwey NA, et al. Assessment of cognition in Parkinson's disease. Neurology 2003;61:1222-8.

83 Morris JN, Fries BE, Mehr DR, et al. Mds cognitive performance scale. J Gerontol 1994;49:M174-82. 